\title{
In reply to: what is new about triticeal cartilage?
}

\author{
Rabia Koca' (D), Zeliha Fazlığulları ${ }^{2}$ \\ ${ }^{1}$ Department of Physical Therapy and Rehabilitation, School of Health Sciences, Afyonkarabisar Health Sciences University, Afyonkarabisar, Turkey \\ ${ }^{2}$ Department of Anatomy, School of Medicine, Selçuk University, Konya, Turkey \\ Anatomy 2020;14(3):232 @2020 Turkish Society of Anatomy and Clinical Anatomy (TSACA)
}

\section{Dear Editor,}

We would like to thank Dr. Vatansever ${ }^{[1]}$ for his interest in our paper and for spending time to express his contributions. His valuable comments provided us significant insight regarding the content and the analysis of our study. ${ }^{[1]}$ We would like to kindly provide further details regarding the newly observed shapes of triticeal cartilages taking the calcification pattern into account.

The study on triticeal cartilage primarily aims to prevent confusion with atheroma plaques, which may occur in the common carotid artery. The atheroma plaques are important to recognize since they have a potential risk of causing stroke and can easily be mixed with calcified triticeal cartilage during the evaluation of radiological images since they both have similar anatomical location. Triticeal cartilage measurements of Koca et al. ${ }^{[2]}$ were made on computed tomography images. The measurements made by Alqahtani et al. ${ }^{[3]}$ and Vatansever et al..$^{[4]}$ were examined on computed tomography angiography and triticeal cartilage was classified according to its shape in a similar pattern. Joshi et al. ${ }^{[5]}$ studied the triticeal cartilage on cadavers and classified the cartilage according to its shape as oval, circular, pyramidal, spindle and cylindrical. ${ }^{[5]}$ However, as shown in the tables and figures of the study by Koca et al., ${ }^{[2]}$ different types of triticeal cartilage were reported as hook, double circle and ring, which were not previously identified. These cartilages were named according to the shapes in which they were observed.

"Ring-shaped triticeal cartilage" was observed in 12 $(7.19 \%)$ out of 167 males, while it was not detected in 65 females $(p=0.02) .^{[2]}$ In the post hoc G-power analysis performed to determine the strength of this difference, the statistical power was calculated as $98.8 \% .^{[6]}$ Ring-shaped cartilage with a cavity may be due to the calcification which started from the outside of the cartilage while the middle was not yet calcified. On the other hand, "double circleshaped triticeal cartilage" was viewed as if the two cartilages were placed on top of one another, although it was actually single. Furthermore, in "hook-shaped triticeal cartilage", the calcification of the cartilages might have started unilaterally from the right or left side as a thin, incomplete round shape like a crescent.

To sum up, triticeal cartilage variations were investigated more comprehensively and new shapes of cartilages were added to the already known types by Koca et al. ${ }^{[2]} \mathrm{We}$ suggest that histological studies in large series of cadavers will be more effective to identify new types and make comment on calcification status of triticeal cartilage.

\section{References}

1. Vatansever A. Letter to the editor: what is new about triticeal cartilage? Anatomy 2020;14:231.

2. Koca R, Fazlıŏulları Z, Keleşoğlu KS, Koplay M, Karabulut AK. Prevalence and clinical significance of the triticeal cartilage. Anatomy 2020;14:97-101.

3. Alqahtani E, Marrero DE, Champion WL, Alawaji A, Kousoubris PD, Small JE. Triticeous cartilage CT imaging characteristics, prevalence, extent, and distribution of ossification. Otolaryngol Head Neck Surg 2016;154:131-7.

4. Vatansever A, Demiryurek D, Tatar I, Ozgen B. The triticeous cartilage redefining of morphology, prevalence and function. Folia Morphol (Warsz) 2018;77:758-63.

5. Joshi MM, Joshi SD, Joshi SS. Prevalence and variations of cartilago triticea. International Journal of Anatomy and Research 2014;2:474-7.

6. Faul F, Erdfelder E, Buchner A, Lang AG. Statistical power analyses using $\mathrm{G}^{*}$ Power 3.1: tests for correlation and regression analyses. Behav Res Methods 2009;41:1149-60.

ORCID ID:

R. Koca 0000-0002-9052-3002;

Z. Fazlıŏulları 0000-0002-5103-090X

deomed.
Correspondence to: Zeliha Fazlıoğulları, PhD

Department of Anatomy, School of Medicine, Selçuk University, Konya, Turkey

Phone: +90 3322243847

e-mail: z_topal@yahoo.com

Conflict of interest statement: No conflicts declared.

This is an open access article distributed under the terms of the Creative Commons Attribution-NonCommercial-NoDerivs 4.0 Unported (CC BY-NC-ND4.0) Licence (http://creativecommons.org/licenses/by-nc-nd/4.0/) which permits unrestricted noncommercial use, distribution, and reproduction in any medium, provided the original work is properly cited. How to cite this article: Koca R, Fazlıogulları Z. In reply to: what is new about triticeal cartilage? Anatomy 2020;14(3):232. 